\title{
Jogos Lúdicos: Uma Ferramenta para a Compreensão da Química Orgânica
}

\author{
Renata J oyce Diniz Silva)* (Graduanda em Química na Universidade Federal de Campina Grande - \\ UFCG); \\ José Carlos Oliveira Santos (Professor da UABQ/CES na Universidade Federal de Campina Grande - \\ UFCG) \\ *E-mail: renatarjds@gmail.com
}

\begin{abstract}
Resumo: Este trabalho destina-se a utilizar os jogos lúdicos como ferramenta avaliativa na aprendizagem da Química Orgânica, numa turma de terceiro ano da Escola Estadual Orlando Venâncio dos Santos, situada no município de Cuité na Paraíba. Para realização dessa intervenção os bolsistas do subprojeto PIBID - Química da UFCG, trabalharam junto com o professor em sala de aula, as funções orgânicas oxigenadas: álcool, aldeído, ácido carboxílico, cetona e fenol. Foram confeccionados dois jogos lúdicos, o jogo da memória e o jogo do percurso. Com o objetivo de facilitar e promover uma aprendizagem significativa, os jogos lúdicos se enquadram dentro de uma proposta de ensino bastante requisitada.
\end{abstract}

Palavras-chave: J ogos educativos; Química Orgânica; ensino; aprendizagem; metodologias inovadoras.

Espaço reservado para organização do congresso. 


\section{I ntrodução}

Durante muito tempo, acreditava-se que a aprendizagem ocorria pela repetição e que os estudantes que não aprendiam eram os únicos responsáveis pela sua falta de sucesso. Hoje, a falta de sucesso dos estudantes também é considerada conseqüência do trabalho do professor. A idéia do ensino despertado pelo interesse do estudante passou a ser um desafio à competência do docente. $\mathrm{O}$ interesse daquele que aprende passou a ser a força motora do processo de aprendizagem, e o professor, o gerador de situações estimuladoras para aprendizagem. É nesse contexto que o jogo didático ganha espaço como instrumento motivador para a aprendizagem de conhecimentos químicos, à medida que propõe estímulo ao interesse do estudante. Se, por um lado, o jogo ajuda este a construir novas formas de pensamento, desenvolvendo e enriquecendo sua personalidade, por outro, para o professor, o jogo o leva à condição de condutor, estimulador e avaliador da aprendizagem (CUNHA, 2012).

A atividade lúdica com objetivo de propiciar o meio para que o aluno induza o seu raciocínio, a reflexão e conseqüentemente a construção do seu conhecimento. Promove a construção do conhecimento cognitivo, físico, social e psicomotor o que o leva a memorizar mais facilmente o assunto abordado. Além disso, desenvolve as habilidades necessárias às práticas educacionais da atualidade. De acordo com Melo (2005), o lúdico é um importante instrumento de trabalho. O mediador, no caso o professor, deve oferecer possibilidades na construção do conhecimento, respeitando as diversas singularidades. Essas atividades oportunizam a interlocução de saberes, a socialização e o desenvolvimento pessoal, social, e cognitivo quando bem exploradas. Quando se cria ou se adapta um jogo ao conteúdo escolar, ocorrerá o desenvolvimento de habilidades que envolvem o indivíduo em todos os aspectos: cognitivos, emocionais e relacionais. Tem como objetivo torná-lo mais competente na produção de respostas criativas e eficazes para solucionar os problemas.

De modo geral, os jogos sempre estiveram presentes na vida das pessoas, seja como elemento de diversão, disputa ou como forma de aprendizado. Desde a antiguidade, filósofos como Platão e Aristóteles já viam a importância da utilização dos jogos como ferramenta de aprendizagem. Nessa época, encontram-se algumas referências da utilização de jogos ou materiais direcionados à aprendizagem das crianças como, por exemplo: doceiras de Roma que faziam pequenas guloseimas em forma de letras para as crianças aprenderem a ler e escrever (KISHIMOTO, 1994). A partir do século $\mathrm{XVI}$, com surgimento do renascimento, os humanistas percebem o valor educativo dos jogos, os quais se incorporam a vida dos jovens e adultos, ocorrendo o nascimento dos jogos educativos.

Os colégios de ordem jesuítica foram os primeiros a colocá-los na sala de aula e utilizá-los como recurso didático. O fundador da companhia de Jesus, Inácio de Loyola, percebe a importância dos jogos de exercício para a formação do indivíduo e o reconhece como instrumento didático. Nessa época (século XVI), um padre franciscano - Thomas Muner - edita uma nova dialética, em forma de um jogo de cartas, pois percebe que essa seria uma maneira eficiente para seus alunos aprenderem tal disciplina, que até então era apresentada de forma tradicional nos textos espanhóis.

No século XVIII, criam-se os jogos destinados a ensinar ciências. Nessa época, estes eram utilizados para que a realeza e a aristocracia aprendessem conteúdos da ciência, porém rapidamente tornam-se populares, deixando de ser um privilegio dos nobres. Também serviam como veículo de divulgação e crítica. Por exemplo, os de tipo trilha contavam a glória dos reis, suas histórias e ações; os de tabuleiro divulgam eventos históricos e eram utilizados como meio de doutrinação popular.

No século XX, passou-se a discutir o papel do jogo na educação. Para Godói et al. (2010), os jogos contribuem para o desenvolvimento intelectual das crianças e tornam-se cada vez mais significativos à medida que estas se desenvolvem. Entretanto, esse recurso, para Piaget, não têm a capacidade de desenvolver conceitos na criança, mas por cumprirem um papel importante no desenvolvimento intelectual, promovem conseqüentemente a aprendizagem conceitual.

Um jogo pode ser considerado educativo quando mantém um equilíbrio entre duas funções: a lúdica e a educativa. Segundo Kishimoto (1994), a lúdica está relacionada ao caráter de diversão e prazer que um jogo propicia. A educativa se refere à apreensão de conhecimentos, habilidade e saberes.

Vários estudos e pesquisas mostram que o Ensino de Química é, em geral, tradicional, centralizando-se na simples memorização e repetição de nomes, fórmulas e cálculos, totalmente desvinculados do dia-a-dia e da realidade em que os alunos se encontram. A Química, nessa situação, torna-se uma matéria maçante e monótona, fazendo com que os próprios estudantes questionem o motivo pelo qual ela lhes é ensinada, pois a química escolar que estudam é apresentada de forma 
totalmente descontextualizada. Por outro lado, quando o estudo da Química faculta aos alunos o desenvolvimento paulatino de uma visão crítica do mundo que os cerca, seu interesse pelo assunto aumenta, pois lhes são dadas condições de perceber e discutir situações relacionadas a problemas sociais e ambientais do meio em que estão inseridos, contribuindo para a possível intervenção e resolução dos mesmos. (SANTANA, 2006; SANTOS et al., 2014).

As atividades lúdicas são práticas privilegiadas para a aplicação de uma educação que vise o desenvolvimento pessoal do aluno e a atuação em cooperação na sociedade. São também instrumentos que motivam, atraem e estimulam o processo de construção do conhecimento, podendo ser definida, de acordo com Soares (2004), como uma ação divertida, seja qual for o contexto lingüístico, desconsiderando o objeto envolto na ação. Se há regras, essa atividade lúdica pode ser considerada um jogo.

Os jogos se caracterizam por dois elementos que apresentam: o prazer e o esforço espontâneo, além de integrarem as várias dimensões do aluno, como a afetividade e o trabalho em grupo. Assim sendo eles devem ser inseridos como impulsores nos trabalhos escolares. Os jogos são indicados como um tipo de recurso didático educativo que podem ser utilizados em momentos distintos, como na apresentação de um conteúdo, ilustração de aspectos relevantes ao conteúdo, como revisão ou síntese de conceitos importantes e avaliação de conteúdos já desenvolvidos (CUNHA, 2004).

É nesse contexto que os bolsistas de Iniciação à Docência se encaixam como promovedores de novas metodologias, os quais auxiliam o professor a inovar sua forma de trabalho, a aproximação da experiência do professor que já está inserido dentro da escola é passada para os bolsistas, os quais aliam a essa experiência novas idéias (SANTOS, 2010). O professor é um mediador do conhecimento e para tal necessita se posicionar como ser responsável a promover a construção do saber dos seus alunos, essa é uma tarefa difícil pela qual a criatividade precisa está presente nas salas de aulas, pois é preciso criar novos métodos, com construção de ferramentas acessíveis para o alunado. A elaboração dos jogos da memória e do percurso foram propostas para que os alunos fossem incentivados a aprender Química Orgânica com facilidade, atingindo também outros objetivos, pois através dos jogos os alunos desenvolvem o raciocínio e reflexão, promovendo o conhecimento cognitivo, físico, social e psicomotor. As aulas ministradas sobre as funções orgânicas oxigenadas (álcool, aldeído, ácido carboxílico, cetona e fenol), tinham por objetivo trabalhar a nomenclatura, estrutura, função orgânica, características, definição e os conceitos químicos dessas funções, para que fossem avaliados através dos jogos do percurso e da memória. Em seguida a turma foi dividida em grupos e os jogos foram aplicados em momentos diferentes, com o intuito de analisar a eficiência dessa ferramenta na verificação de aprendizagem da turma envolvida nessa intervenção. Após a elaboração, confecção e aplicação dos jogos, foi possível atingir as funções dos jogos lúdicos, foi visto a facilidade de aprendizagem dos alunos, os quais interagiram entre si, partilhando seu conhecimento com seu grupo para poder participar dos jogos, através da brincadeira o conhecimento foi avaliado e confirmado que esse é um método viável e prazeroso que envolve os alunos uns com os outros, a participar, interagir e atentar para a importância de se obter o conhecimento químico.

O uso de novas metodologias no ensino de Química se faz necessário devido à complexidade envolvida no estudo dessa disciplina. É um desafio pelo qual o professor precisa passar para poder inovar e facilitar com ferramentas capazes de promover o ensino-aprendizagem de maneira significativa. É necessário que se crie metodologias acessíveis e de baixo custo, assim sendo, foi proposto à construção de dois diferentes jogos lúdicos como um método viável para possibilitar a aprendizagem de Química Orgânica para os alunos do Ensino Médio e Inovador da Escola Estadual Orlando Venâncio dos Santos.

\section{Metodologia}

Em virtude das inúmeras contribuições ocasionadas através da ludicidade foi proposto a criação de dois diferentes jogos lúdicos sobre Química Orgânica, essa ferramenta didática foi proposta para utilização pelos alunos do $3^{\circ}$ ano B, do Ensino Médio e Inovador da Escola Estadual Orlando Venâncio dos Santos, situada na cidade de Cuité-PB. A turma selecionada continha um total de trinta alunos.

A proposta foi utilizar os jogos como método avaliativo da aprendizagem. Inicialmente foi trabalhado o conteúdo em sala de aula, através do uso de projetor durante as aulas para apresentar os conteúdos referentes ao jogo, as funções orgânicas estudadas foram álcool, ácido carboxílico, aldeído, 
cetona e fenol. As aulas foram ministradas por bolsistas do PIBID, durante as aulas do macro campo de Iniciação Científica e Pesquisa, essas aulas destinavam-se a demonstração das funções orgânicas, suas nomenclaturas, classe funcional, características, definições e importância no cotidiano dos alunos.

Os jogos didáticos utilizados foram o jogo da memória no qual os alunos se organizaram em grupos e realizaram a pesquisa das estruturas químicas das funções orgânicas para a montagem das peças que relacionam as fórmulas estruturais à nomenclatura ou a função orgânica e o jogo do percurso que consiste num tapete com fases progressivas onde os alunos são as próprias peças e avançam à medida que vão respondendo corretamente as questões lançadas.

Para a produção do jogo da memória os alunos foram divididos em cinco grupos, os quais foram direcionados a realizar pesquisas referentes a fórmulas estruturais, nomenclaturas e funções orgânicas. Cada grupo destinou-se a pesquisar uma das funções orgânicas que haviam estudado em sala de aula, desse modo, o grupo 1 ficou responsável pela função orgânica álcool, o grupo 2 ficou responsável pela função orgânica aldeído, o grupo 3 pela função orgânica ácido carboxílico, o grupo 4 pela função orgânica cetona e o grupo 5 pela função orgânica fenol. Após as pesquisas realizadas pelos alunos, eles foram responsáveis pela produção e confecção do jogo. Cada grupo fez uma parte do jogo pertinente a função orgânica que pesquisaram, foram elaboradas por cada grupo 20 fichas, em quais 5 fichas eram representadas pelo nome de cada função orgânica (álcool,aldeído, ácido carboxílico, cetona e fenol), 10 fichas por diferentes estruturas da respectiva função orgânica (álcool,aldeído, ácido carboxílico, cetona e fenol) e 5 fichas com diferentes nomenclaturas de cada função orgânica (álcool,aldeído, ácido carboxílico, cetona e fenol). Sendo que 5 estruturas se relacionavam com a nomenclatura, e as outras 5 estruturas se relacionavam com o nome de cada função orgânica.

A confecção das fichas do Jogo da memória foi realizada em sala de aula, os bolsistas do PIBID levaram para a sala cartolina guache, folha de ofício, tesouras e colas. Enquanto os alunos levaram os dados de suas pesquisas necessários para a produção das fichas. Cada grupo formou uma parte do jogo, pois cada grupo ficou responsável por produzir 20 fichas sobre cada função orgânica. Depois da produção feita pelos alunos, os bolsistas misturaram as fichas de modo que se unificasse as fichas e o jogo fosse constituído por todas as funções orgânicas, foram separadas 4 fichas de cada função orgânicas que se relacionassem, dessa maneira como foram trabalhadas e elaboradas fichas com 5 funções orgânicas, foi possível construir 5 jogos da memória com vinte peças cada um.

O jogo da memória foi utilizado como instrumento avaliativo através de uma gincana, cada grupo ficou com um jogo da memória para jogar entre os alunos do seu grupo, eles misturavam as fichas sem que as vissem em seguida tentavam memorizar quais fichas se relacionavam, em seguida, cada grupo elegia um componente como ganhador, os quais disputavam o jogo com um aluno de outro grupo na semifinal, os alunos dos diferentes grupos disputaram de modo que só restaram dois alunos para a grande final. Os alunos selecionados para a final jogaram o jogo da memória novamente, e no término do jogo foi eleito um ganhador que representava seu grupo.

O Jogo do percurso também foi utilizado como instrumento avaliativo, o jogo funcionou da seguinte maneira: foi criado um tapete feito com TNT, decorado com EVA, de modo que, o tapete continha um percurso, o qual se seguia de forma progressiva quando os alunos respondessem corretamente as perguntas propostas pelos bolsistas, foram elaboradas 20 perguntas referentes aos conteúdos vistos em sala de aula sobre as funções orgânicas (álcool, aldeído, ácido carboxílico, cetona e fenol). Novamente a turma foi dividida em grupos, cada grupo continha um representante, num total de quatro representantes dos seus respectivos grupos. Cada representante funcionava como uma peça do jogo, as perguntas eram feitas e o cada grupo poderia ajudar o seu representante, se eles acertassem jogavam um dado que indicava quantas casas eles podiam prosseguir no percurso do tapete. Dois representantes seguiram pelo lado direito do percurso, enquanto os outros dois seguiram pelo lado esquerdo do percurso, o aluno que atingisse primeiro a última casa do percurso do tapete ganhava o jogo.

\section{Resultados e Discussão}

Com base na proposta da criação de dois diferentes jogos lúdicos para serem usados como ferramenta avaliativa nos conteúdos de Química Orgânica, foram realizadas na Escola Estadual Orlando Venâncio dos Santos, aulas expositivas para a aprendizagem de cinco funções orgânicas (álcool, aldeído, ácido 
carboxílico, cetona e fenol), as quais serviram para que os alunos fortificassem os seus conhecimentos prévios adquiridos durante as aulas de Química, em seguida, foram confeccionados e usados o jogo da memória e o jogo do percurso para efetivar a fixação do conteúdo, avaliando de forma prazerosa qual a qualidade de aprendizagem dos alunos com uma metodologia diferente da tradicional, sabemos que pelos alunos as provas são consideradas difíceis e muitas vezes chatas ou exaustivas, diante disso os jogos foram propostos para facilitar e promover o conhecimento de maneira simples, descontraída e empolgante.

No jogo da memória, os alunos mostraram suas habilidades/competências adquiridas no estudo da Química Orgânica, de maneira descontraída, jogavam com seus colegas e selecionavam as fichas para a devida memorização que se relacionassem, demonstraram domínio dos conteúdos, sabendo relacionar com facilidade as fichas adequadas referentes à estrutura, nomenclatura e nome de cada função orgânica, conforme imagens mostradas na Figura 1.

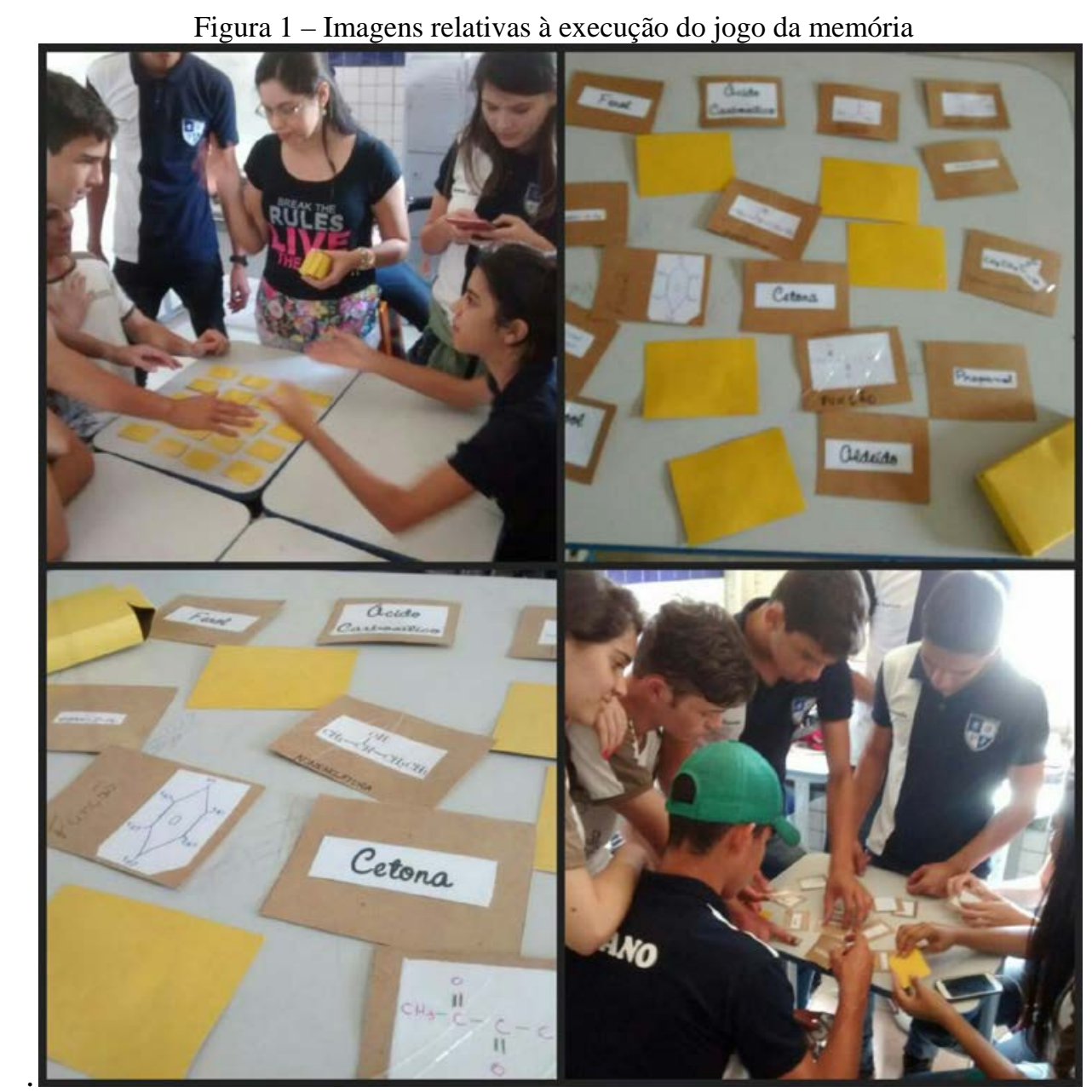

Fonte: autoria própria (2015).

Para realização do jogo do percurso, inicialmente, foram criadas 20 perguntas referentes as funções orgânicas estudadas, (álcool, aldeído, ácido carboxílico, cetona e fenol). As perguntas seguem no Quadro abaixo.

Quadro 1 - Conjunto de perguntas referentes ao jogo do percurso.

Pergunta: Escreva a fórmula estrutural do $\quad$ Pergunta: Qual a nomenclatura da estrutura 2-metil-propanol. do seguinte ácido? 


\begin{tabular}{|c|c|}
\hline 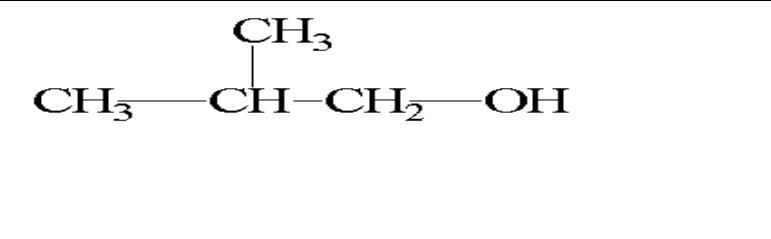 & 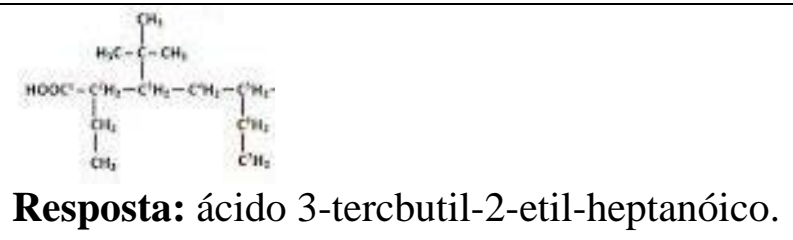 \\
\hline $\begin{array}{l}\text { Pergunta: Quais os fatores caracterizam a } \\
\text { função orgânica oxigenada “Álcool”? } \\
\text { Resposta: cadeia carbônica contendo uma } \\
\text { ou mais hidroxilas (OH) ligadas diretamente } \\
\text { a um carbono saturado (isto é, carbono que } \\
\text { só faz ligações simples). }\end{array}$ & $\begin{array}{l}\text { Pergunta: qual a nomenclatura usual do ácido } \\
\text { acético? } \\
\text { Resposta: vinagre. }\end{array}$ \\
\hline $\begin{array}{l}\text { Pergunta: Qual a nomenclatura da seguinte } \\
\text { estrutura? } \\
\text { Resposta: Etan-1,2-diol }\end{array}$ & $\begin{array}{l}\text { Pergunta: Qual a estrutura da seguinte } \\
\text { nomenclatura (ácido butanodióico)? } \\
\text { Resposta: }\end{array}$ \\
\hline $\begin{array}{l}\text { Pergunta: Diga o nome e faça a estrutura } \\
\text { molecular do álcool presente nas bebidas } \\
\text { alcoólicas. } \\
\text { Resposta: Etanol, CH3CH2OH. }\end{array}$ & $\begin{array}{l}\text { Pergunta: Qual a nomenclatura da seguinte } \\
\text { estrutura? } \\
\mathrm{H}_{3} \mathrm{C}-\mathrm{CH}_{2}^{-}-\mathrm{CH}_{2}-\mathrm{CH}_{2}-\mathrm{CH}_{2}^{-} \mathrm{C}_{\mathrm{OH}} \\
\text { Resposta: Ácido hexanóico }\end{array}$ \\
\hline $\begin{array}{l}\text { Pergunta: Qual a estrutura da seguinte } \\
\text { nomenclatura 2-etil-4metil-pentanal? } \\
\text { Resposta: }\end{array}$ & $\begin{array}{l}\text { Pergunta: Qual a nomenclatura da seguinte } \\
\text { estrutura? } \\
\text { Resposta: 2-etil-4-metil-octanal. }\end{array}$ \\
\hline $\begin{array}{l}\text { Pergunta: Qual a nomenclatura da seguinte } \\
\text { estrutura? }\end{array}$ & $\begin{array}{l}\text { Pergunta: Qual a estrutura da seguinte } \\
\text { nomenclatura (4,6-dimetil-octan-2-ona)? } \\
\text { Resposta: }\end{array}$ \\
\hline $\begin{array}{l}\text { Pergunta: Qual a nomenclatura da seguinte } \\
\text { estrutura? }\end{array}$ & $\begin{array}{l}\text { Pergunta: Escreva a fórmula estrutural do 4- } \\
\text { metil-fenol. }\end{array}$ \\
\hline
\end{tabular}




\begin{tabular}{|c|c|}
\hline $\begin{array}{c} \\
\mathbf{H}_{\mathbf{3}} \mathbf{C}-\mathbf{C H}_{\mathbf{2}}-\mathbf{C H}_{\mathbf{2}}-\underset{\mathrm{C}}{\mathrm{C}}-\stackrel{O}{\mathrm{C}}-\mathbf{C H}_{\mathbf{3}} \\
\mathrm{HC}-\mathrm{CH}_{3} \\
\mathrm{I} \\
\mathrm{CH} \\
\text { Resposta: 3-isopropil-hexan-2-ona. }\end{array}$ & Resposta: \\
\hline $\begin{array}{l}\text { Pergunta:Escreva a fórmula estrutural do } \\
\text { 2,3-dimetil- } \\
\text { butanal. }\end{array}$ & $\begin{array}{l}\text { Pergunta: Quantos átomos de carbono } \\
\text { secundário há na cadeia carbônica do 2- } \\
\text { pentanol? } \\
\text { Resposta: } 3\end{array}$ \\
\hline $\begin{array}{l}\text { Pergunta: Quais os fatores caracterizam a } \\
\text { função orgânica oxigenada "Fenol"? } \\
\text { Resposta: Conter hidroxila (OH) ligada } \\
\text { diretamente a um anel aromático. }\end{array}$ & $\begin{array}{l}\text { Pergunta:Escreva a fórmula estrutural do 3- } \\
\text { metil-fenol: } \\
\text { Resposta: }\end{array}$ \\
\hline $\begin{array}{l}\text { Pergunta: Qual a nomenclatura do seguinte } \\
\text { composto orgânico? } \\
\text { Resposta: 2-etil-3-metil-fenol. }\end{array}$ & $\begin{array}{l}\text { Pergunta: Quais fatores caracterizam a função } \\
\text { orgânica oxigenada "Aldeído"? } \\
\text { Resposta: Os aldeídos se caracterizam pela } \\
\text { presença do grupo funcional -CHO na } \\
\text { molécula. }\end{array}$ \\
\hline
\end{tabular}

Fonte: autoria própria (2015).

Para a execução do jogo do percurso, as perguntas do Quadro 1 foram colocadas dentro de uma caixa, em seguida, os bolsistas retiravam uma das perguntas e liam em voz alta para um representante de cada grupo, o qual ouvia com atenção e discutia com seu grupo qual a melhor resposta para a pergunta proposta, o representante ia até o quadro na frente da sala e mostrava para todos os colegas a qual resposta seu grupo havia chegado, a professora juntamente com os bolsistas anunciavam se a resposta estava certa ou errada, caso a resposta estivesse correta o aluno poderia jogar um dado que representava quantas casas ele poderia avançar, caso a resposta estivesse errada o aluno não poderia jogar o dado para prosseguir nenhuma casa. Ao longo do percurso tinham algumas prendas pelas quais os alunos havia que passar, por exemplo, volte "n" casas no percurso, imite um professor, conte uma piada, pague um mico proposto pelo colega que estiver mais adiante ao longo do percurso, avance "n" casas. Como foram posicionados dois alunos por cada lado do percurso, dois do lado direito e dois do lado esquerdo, o aluno que atingisse primeiro o outro lado ganharia o jogo, assim, um dos lados da direita ou um dos alunos da esquerda tinha que chegar no fim da trilha do lado oposto ao que havia começado para poder ser eleito um ganhador, o qual representava um dos quatro grupos que haviam sido formados.

Através do jogo do percurso como instrumento de avaliação da aprendizagem foi possível analisar a eficiência do saber compartilhado com a diversão, os alunos foram mais envolvidos no processo de aprendizagem, pois havia motivação para demonstrar que a sua compreensão a cerca da Química Orgânica era eficiente frente as perguntas propostas, o jogo teve um papel fundamental para que os alunos pudessem expressar o aprendizado atingido durante as aulas, além de promover o trabalho em equipe, a divisão de saberes e a construção de um conhecimento compartilhado com os seus colegas. Os alunos se mostraram motivados e protagonistas do saber científico necessário na atividade em que estavam envolvidos, percebendo que a Química é um conhecimento presente na sua realidade e que é 
possível aprender a construir o seu saber sobre essa disciplina de forma confortável e descontraída (Figura 2).

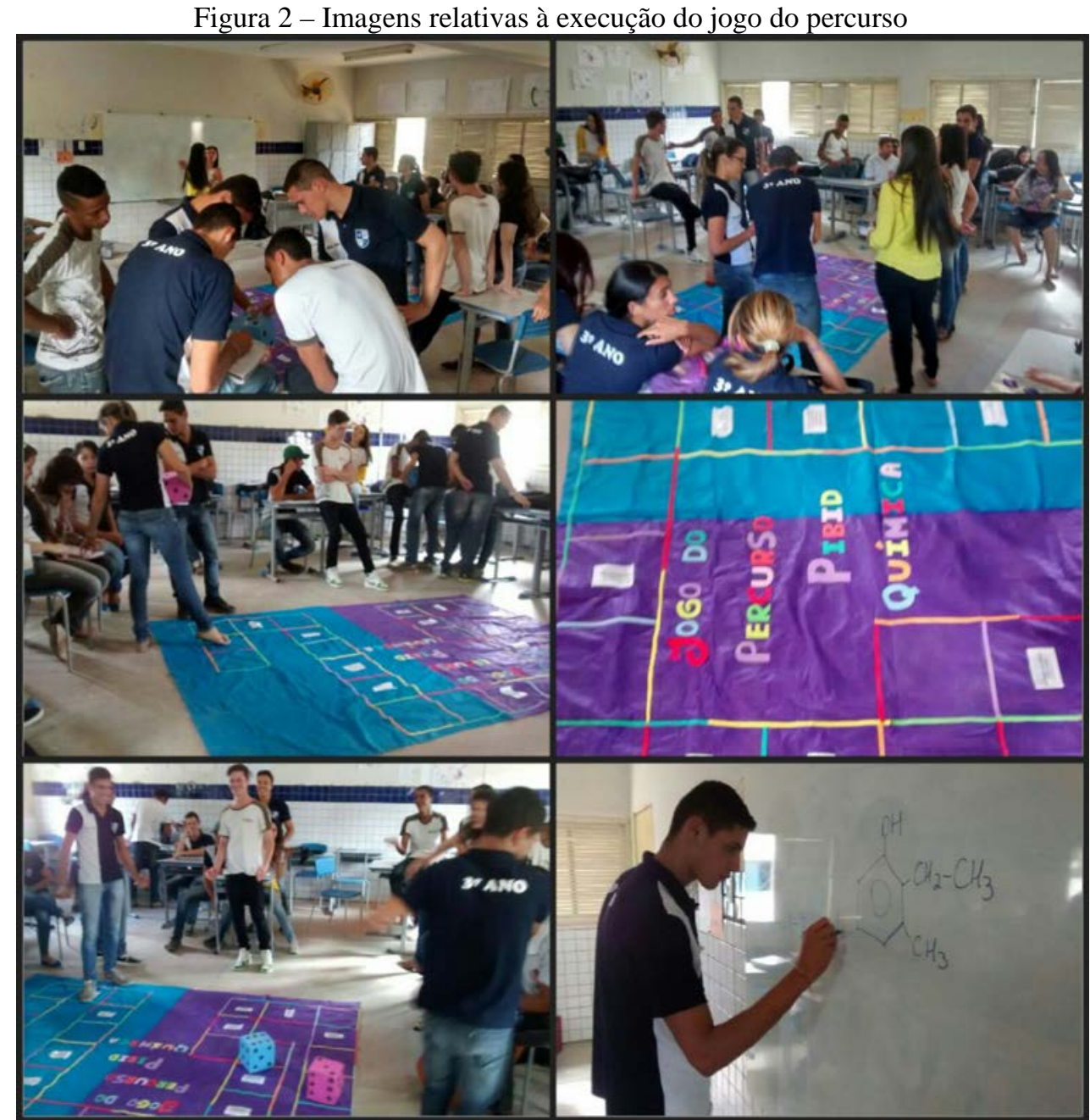

Fonte: autoria própria (2015).

\section{Conclusões}

A construção do jogo da memória e do jogo do percurso possibilitou atingir os objetivos que são buscados quando se utiliza um jogo lúdico voltado para o ensino, foi possível estabelecer o conhecimento científico harmonizado com a brincadeira, a Química Orgânica ficou clara para os alunos envolvidos nesse processo de aprendizagem, isso foi visto durante a execução dos jogos, pois os alunos mostraram um conhecimento firme sobre as funções orgânicas oxigenadas estudadas (álcool, aldeído, ácido carboxílico, cetona e fenol), foi desenvolvido através do esforço de cada um dos alunos conhecimento coletivo.

Os jogos auxiliam os alunos a desenvolverem além do conhecimento, o trabalho em grupo, a afetividade pelos seus colegas, o respeito, a interação e sobre tudo o conhecimento químico vinculado ao modo de aprender com facilidade o que era antes classificado como chato ou exaustivo, foi perceptível na execução dos jogos, a participação, a interação e a necessidade de saber com firmeza os conteúdos estudados, isso incentiva e atrai o aluno para permanecer na escola e atingir as habilidades e competências que lhe são necessárias para sua vida em sociedade, para o ensino de Química da atualidade é necessário resgatar o aluno e mostrar-lhe que a Ciência é capaz de ser aprendida com prazer, os jogos lúdicos desempenham essa função com facilidade e auxiliam o professor como mediador do conhecimento científico necessário a ser transmitido para os alunos. 
Playful games: A Tool for Organic Chemistry Understanding

Abstract: This work is intended to use the games as an evaluative tool playful learning of organic chemistry, a class of third year of the State School Venancio Orlando dos Santos, located in Cuité municipality in Paraíba. To carry out this intervention fellows subproject PIBID - Chemistry UFCG, they worked together with the teacher in the classroom, the oxygenated organic functions: alcohol, aldehyde, carboxylic acid, ketone and phenol. Two fun games were made, the memory game and the course of the game. In order to facilitate and promote meaningful learning, fun games fall within a fairly ordered educational proposal.

Keywords: Educational games; Organic chemistry; education; learning; innovative methodologies.

\section{Referências bibliográficas}

CUNHA, M. B. J ogos no ensino de química: considerações teóricas para sua utilização em sala de aula. Química Nova na Escola, v. 34, n. 2, maio 2012.

GODOI, T. A. F.; OLIVEIRA, H. P. M.; GODOGNOTO, L. Tabela periódica - Um super trunfo para alunos do ensino fundamental e médio. Química Nova na Escola, vol. 32 o1, p. 22-25, 2010.

KISHIMOTO, T. M. O jogo e a educação infantil. São Paulo: Pioneira, 1994.

MELO,C. M. R. As atividades lúdicas são fundamentais para subsidiar ao processo de construção do conhecimento. Información Filosófica. V.2, №1, p.128-133, 2005.

SANTANA, E. M. A I nfluência de atividades lúdicas na aprendizagem de conceitos químicos. Universidade de São Paulo, Instituto de Física - Programa de Pós-Graduação Interunidades em Ensino de Ciências, 2006.

SANTOS, F. A. C.; MELO, F. M. A.; SANTOS, J. C. O. Explorando o Ensino de Química no Ensino Médio: Levantamentos do PIBID/Química Quanto à Motivação e Principais Dificuldades na Aprendizagem de Alunos do 1을 ao 3o Ano. In: Anais do 54 Congresso Brasileiro de Química, Natal: ABQ, 2014.

SANTOS, J. C. O. Dominó Químico: Uma Ferramenta Lúdica Para o Ensino-Aprendizagem em Química. In: Anais do 8o Simpósio Brasileiro de Educação Química, Natal - RN: 2010. 